\title{
BMJ Open Haemoglobin A1c and hearing impairment: longitudinal analysis using a large occupational health check-up data of Japan
}

\author{
Satsue Nagahama, ${ }^{1,2,3}$ Ikuko Kashino, ${ }^{3}$ Huanhuan Hu, ${ }^{3}$ Akiko Nanri, ${ }^{4}$ \\ Kayo Kurotani, ${ }^{5}$ Keisuke Kuwahara, ${ }^{3,6}$ Masashi Dan, ${ }^{2}$ Takehiro Michikawa, ${ }^{7}$ \\ Shamima Akter, ${ }^{3}$ Tetsuya Mizoue, ${ }^{3}$ Yoshitaka Murakami, ${ }^{8}$ Yuji Nishiwaki ${ }^{1}$
}

To cite: Nagahama S, Kashino I, $\mathrm{Hu} \mathrm{H}$, et al. Haemoglobin A1c and hearing impairment: longitudinal analysis using a large occupational health checkup data of Japan. BMJ Open 2018;8:e023220. doi:10.1136/ bmjopen-2018-023220

- Prepublication history and additional material for this paper are available online. To view these files, please visit the journal online (http://dx.doi org/10.1136/bmjopen-2018023220).

Received 29 March 2018 Revised 31 July 2018 Accepted 4 August 2018
Check for updates

(C) Author(s) (or their employer(s)) 2018. Re-use permitted under CC BY-NC. No commercial re-use. See rights and permissions. Published by BMJ.

For numbered affiliations see end of article.

Correspondence to Dr Satsue Nagahama; satsue-n@umin.ac.jp

\section{ABSTRACT}

Objectives The aim of this study was to determine whether haemoglobin $\mathrm{A} 1 \mathrm{c}(\mathrm{HbA} 1 \mathrm{c})$ level is associated with the incidence of hearing impairment accounting for smoking status and diabetic condition at baseline.

Methods Participants were 131689 men and 71286 women aged 30-65 years and free of hearing impairment at baseline (2008) who attended Japanese occupational annual health check-ups from 2008 to 2015 . We defined low-frequency hearing impairment at a hearing threshold $>30 \mathrm{~dB}$ at $1 \mathrm{kHz}$ and high frequency at $>40 \mathrm{~dB}$ at $4 \mathrm{kHz}$ in the better ear in pure-tone audiometric tests. HbA1c was categorised into seven categories. The association between $\mathrm{HbA1C}$ and hearing impairment was assessed using the Cox proportional hazards model.

Results On 5 years mean follow-up, high $\mathrm{HbA1c}$ was associated with high-frequency hearing impairment. In non-smokers, $\mathrm{HbA1c} \geq 8.0 \%$ was associated with highfrequency hearing impairment, with a multivariable $\mathrm{HR}$ (95\% Cl) compared with $\mathrm{HbA} 1 \mathrm{c} 5.0 \%-5.4 \%$ of 1.46 (1.10 to 1.94) in men and 2.15 (1.13 to 4.10 ) in women. There was no significant association between $\mathrm{HbA} 1 \mathrm{c}$ and hearing impairment in smokers. A J-shaped association between $\mathrm{HbA} 1 \mathrm{c}$ and high-frequency hearing impairment was observed for participants with diabetes at baseline. HbA1c was not associated with low-frequency hearing impairment among any participants.

Conclusions $\mathrm{HbA} 1 \mathrm{c} \geq 8.0 \%$ of non-smokers and $\geq 7.3 \%$ of participants with diabetes was associated with highfrequency hearing impairment. These findings indicate that appropriate glycaemic control may prevent diabeticrelated hearing impairment.

\section{BACKGROUND}

Patients with hearing impairment experience a range of complications, including impaired quality of life, dementia, depression, loneliness, poor self-esteem and functional disability. ${ }^{1-4}$ These complications have made this condition a social and economic problem worldwide. More than 5\% of the world population has hearing impairment, and this is expected to increase with the ageing of the
Strengths and limitations of this study

- This study included a large number of participants, accounting for gender and smoking status.

- A median follow-up period was 5 years.

- This study findings are limited to workers in Japan.

- We investigated whether haemoglobin A1c was associated with hearing impairment among participants with diabetes at baseline.

- Information on noise exposure, ototoxic drug use, ear surgery and ear infection was not obtained.

population. ${ }^{5}$ Although this bleak picture points to the importance of identifying preventable risk factors for hearing impairment, such studies are in fact scarce.

Emerging evidence suggests that diabetes mellitus may be a risk factor for hearing impairment. Meta-analyses of 13 cross-sectional studies showed that subjects with diabetes had a twofold increased risk of developing hearing impairment (OR 2.15, 95\% CI 1.72 to 2.68$).{ }^{6}$ Diabetic hearing impairment is hypothesised to be due to microvascular complications. $^{78}$ Diabetic hearing impairment may thus be prevented by appropriate glycaemic control, which has been shown to be effective for other microvascular complications of diabetes, such as retinopathy, nephropathy and neuropathy. ${ }^{9-12}$ Three studies have reported the association between hearing impairment and haemoglobin A1c (HbA1c), an indicator for glycaemic control. $^{13-15}$ One of these reported a positive dose-response relationship between HbA1c and hearing impairment as defined using a pure-tone average threshold of mainly low frequencies, ${ }^{15}$ while the other two reported that $\mathrm{HbAlc}$ was positively associated with high-frequency hearing impairment. ${ }^{13} 14$ Nevertheless, no study has yet reported the 
precise shape of the dose-response relationship between HbA1c and high-frequency hearing impairment. Furthermore, no study has yet investigated whether HbAlc is associated with hearing impairment among those with diabetes.

In Japan, a pure-tone audiometric test is mandatory in annual occupational health check-ups. ${ }^{16}$ The large sample size this affords has enabled us to investigate the dose-response relationship between HbAlc and hearing impairment, while accounting for well-known risk factors of hearing impairment such as gender and smoking. ${ }^{17} 18$ The present study had two aims. The first aim was to investigate the association between HbA1c and the incidence of hearing impairment using a large dataset from annual occupational health check-ups in Japan, accounting for gender and smoking status. The second aim was to determine whether HbAlc was associated with hearing impairment among participants with diabetes.

\section{METHODS}

\section{Study population}

The present study was conducted using data from annual health check-ups of Japanese workers. The All Japan Labor Welfare Foundation, a health service provider with centres in Tokyo, Aomori, Nagano, Yamagata, Ibaraki, Gunma and Nagoya provided the data from April 2008 to December 2015, allowing a maximum of 7 years of follow-up. In Japan, annual health check-ups are mandatory for all employees and include a hearing test under the Industrial Safety and Health Act. Nearly all employees attend a health check-up every year. Participants were mainly Japanese employees but also included a small number of their dependents, employers and foreign workers.

A total of 312512 participants aged 30-65 years underwent a hearing test and HbAlc test at baseline (between April 2008 and March 2009). Of these, we excluded participants with hearing impairment at baseline $(\mathrm{n}=51489)$. Given that patients with diabetes with complications may receive more intensive treatments, which may bias the association between HbAlc and hearing impairment, we excluded participants with cardiovascular disease and stroke $(n=913)$. We further excluded participants who did not attend any subsequent health examinations or hearing tests $(\mathrm{n}=48618)$. After further exclusion of 8517 participants with missing information on covariates (5011 for smoking status, 5152 for alcohol consumption, 1815 for physical activity data, 5 for body mass index (BMI), 9 for hypertension and 9 for dyslipidaemia data; some participants had missing data for more than one parameter), leaving 202975 participants (131689 men and 71286 women) for analysis.

Before March 2013, we disclosed the purpose of our study by posters and the participants had the opportunity to refuse the use of their data for the study. This procedure conforms to the Japanese Ethical Guidelines for Medical and Health Research Involving Human Subjects, where the obtaining consent may be simplified for observational studies using existing data.

\section{Ascertainment of hearing impairment}

Trained staff performed pure-tone air-conduction audiometry using an audiometer (AA-57, RION, Tokyo, Japan). Low-frequency hearing impairment was defined as failure to hear a pure-tone signal of $30 \mathrm{~dB}$ at $1 \mathrm{kHz}$ in the better ear, and high-frequency hearing impairment as failure to hear a pure-tone signal of $40 \mathrm{~dB}$ at $4 \mathrm{kHz}$ in the better ear. These thresholds are recommended for use in annual health check-ups by Ministry of Health, Labour and Welfare in Japan. ${ }^{16}$ Onset of hearing impairment was defined as the day of the health check-up on which hearing impairment was first detected.

\section{Data collection and measurements at baseline (between April 2008 and March 2009)}

We used a self-administered questionnaire developed by the Ministry of Health, Labour and Welfare for a specific health examination, namely the national health check-up system focused on metabolic syndrome,${ }^{19}$ to assess medical history, regular physical activity (walking time $<60 \mathrm{~min}$ / day or $\geq 60 \mathrm{~min} /$ day), smoking status (non-smoker, daily smoker $\leq 20$ cigarettes/day or $>20$ cigarettes/day), alcohol consumption (non-drinker, $<1$ go, 1 to $<2$ go or $\geq 2$ go/day; 1 go of sake, a traditional Japanese beverage, is equal to about $180 \mathrm{~mL}$ of $10 \%-14 \%$ ethanol and contains about $23 \mathrm{~g}$ of ethanol), ${ }^{20}$ and self-reported diabetes (treatments with antidiabetic medication or a self-reported history of diabetes: yes or no). Job type was categorised as professional job, management, office job, sales, service, telegraph, manufacturing, transportation and other. Height was measured to the nearest $0.1 \mathrm{~cm}$ and weight to the nearest $0.1 \mathrm{~kg}$. BMI was calculated as the weight in kilograms divided by the square of height in metres and categorised into four groups $(<18.5,18.5-22.9$, 23-29.9 and $\left.\geq 30 \mathrm{~kg} / \mathrm{m}^{2}\right)$. Blood pressure was measured in the sitting position using an automated sphygmomanometer (HEM-907, Omron, Kyoto, Japan). Participants with high blood pressure $(\geq 130 \mathrm{~mm} \mathrm{Hg}$ systolic or $\geq 85 \mathrm{~mm} \mathrm{Hg}$ diastolic) received a second measurement and the average was used for the analysis. Hypertension was defined by $\geq 140 \mathrm{~mm} \mathrm{Hg}$ systolic, $\geq 90 \mathrm{~mm} \mathrm{Hg}$ diastolic or the use of medication for hypertension. A venous blood sample was collected and stored in a cooler at $4^{\circ} \mathrm{C}$ for transportation to an external laboratory (SRL, Tokyo, Japan). Triglyceride level was measured using an enzymatic colorimetric test and high-density lipoprotein cholesterol (HDL-C) was determined using a direct method. Dyslipidaemia was defined by triglyceride $\geq 150 \mathrm{mg} / \mathrm{dL}(1.7 \mathrm{mmol} / \mathrm{L})$ in men and women, HDL-C $<40 \mathrm{mg} / \mathrm{dL}(1.04 \mathrm{mmol} / \mathrm{L})$ in men and $<50 \mathrm{mg} / \mathrm{dL}(1.3 \mathrm{mmol} / \mathrm{L})$ in women or use of medication for dyslipidaemia. HbAlc was measured by latex agglutination turbidimetry and converted to the National Glycohemoglobin Standardization Program equivalent value (\%) using the formula below, according to the Japan Diabetes Society statement ${ }^{21}$ : 
HbA1c $(\%)=1.02 \times$ HbA1c (Japan Diabetes Society) $(\%)+0.25 \%$

Diabetes was defined as FPG $\geq 126 \mathrm{mg} / \mathrm{dL}, \mathrm{HbAlc} \geq 6.5 \%$ or self-reported diabetes.

\section{Statistical analysis}

Participants were divided into seven groups according to their HbA1c level at baseline $(<5.0 \%(91 \mathrm{mg} / \mathrm{dL}), 5.0 \%-$ $5.4 \% \quad(91-110 \mathrm{mg} / \mathrm{dL}), \quad 5.5 \%-5.9 \% \quad(111-125 \mathrm{mg} / \mathrm{dL})$, $6.0 \%-6.4 \% \quad(126-139 \mathrm{mg} / \mathrm{dL}), \quad 6.5 \%-6.9 \% \quad(140-153 \mathrm{mg} /$ dL), $7.0 \%-7.9 \%(154-182 \mathrm{mg} / \mathrm{dL}), \geq 8.0 \%(183 \mathrm{mg} / \mathrm{dL}))$. The HbAlc group specific baseline characteristics of participants were described as means (SD) for continuous variables and percentages for categorical variables. Personyear was calculated from baseline to the onset of hearing impairment, or the date of the last health check-up to December 2015 (whichever occurred first). Crude incident rates of hearing impairment were shown in events per 1000 person-years. Survival analyses were performed using Cox regression to estimate the HR with $95 \%$ CI for the incidence of hearing impairment across HbAlc categories, with $5.0 \%-5.4 \%(31-36 \mathrm{mmol} / \mathrm{mol})$ as the reference value. The analyses were stratified by sex because the interaction between hearing impairments and sex was significant ( $p$ for interaction $<0.001)$. Age-adjusted model (model 1 ) and multiple-adjusted model (model 2), which included alcohol consumption, physical activity, BMI, hypertension, dyslipidaemia, self-reported diabetes and smoking status were used for the analysis. Although smoking status itself was related to hearing impairment in this study, the association between HbA1c and hearing impairment differed according to smoking status ( $p$ for interaction $<0.001$ ). We, therefore, additionally performed analyses according to combined HbAlc (seven groups) and smoking status (non-smoker and current smoker), by considering HbAlc $5.0 \%-5.4 \%(31-36 \mathrm{mmol} / \mathrm{mol})$ and non-smoker as the reference category. We did not analyse women's smokers because of the small number of cases. To assess whether control of HbA1c would reduce the incidence of hearing impairment in those with diabetes, we elucidated the shape of the relationship between HbA1c and high-frequency hearing impairment among those with diabetes. We fitted restricted cubic splines models with seven knots placed at the 1 th, 5th, 25th, 50th, 75th, 95th and 99th centiles as reference values of HbA1c $6.6 \%$ (25th). ${ }^{22}$ The HRs were adjusted for alcohol consumption, physical activity, BMI, hypertension, dyslipidaemia and smoking status. As a sensitivity analysis, we further adjusted for job type in the main analyses (model 2) among participants with this information $(n=126823)$. We tested the proportional hazards assumption using Schoenfeld residuals. We found no significant deviations for any covariate. $P$ value of two-tailed test $<0.05$ was considered statistically significant. Trend association was assessed by assigning ordinal numbers $(0-6)$ to the HbA1c categories. We calculated the $\mathrm{p}$ for the quadratic trend because it was a better fit for the data than the simple linear model. All statistical analyses were performed using Stata V.12.1 (StataCorp).

\section{Patient and public involvement}

No patient and public were involved in setting the research question or the outcome measures, planning for the design of the study.

\section{RESULTS}

Baseline characteristics by category of HbAlc are shown in table 1 . The mean age of participants was 45 years for men and 47 years for women. Participants who had higher HbAlc tended to be non-drinkers and to have higher BMI, hypertension and dyslipidaemia in both men and women. Male participants with higher HbAlc tended to be smokers consuming $>20$ cigarettes per day.

In men, 4621 developed high-frequency hearing impairment with 661937 person-years (mean duration of follow-up was 5.0 years) and 1311 developed low-frequency hearing impairment with 670153 person-years (5.1 years). In women, 582 developed high-frequency hearing impairment with 345312 person-years ( 4.8 years) and 1207 developed low-frequency hearing impairment with 344057 person-years ( 4.8 years). Table 2 shows the association between $\mathrm{HbAlc}$ and the incidence of hearing impairment. In the multivariable-adjusted model, HbAlc showed a quadratic trend with the incidence of high-frequency hearing impairment in men ( $p$ for quadratic $=0.007)$, and a statistically marginal association in women ( $p$ for quadratic $=0.08$ ). HbA1c was not associated with low-frequency hearing impairment. Figure 1 shows the association between HbAlc and high-frequency hearing impairment with accounting for smoking status (the interaction between HbAlc and smoking status ( $p$ for interaction $<0.001)$ ). Compared with non-smokers with $\mathrm{HbAlc} 5.0 \%-5.4 \%(31-36 \mathrm{mmol} / \mathrm{mol})$, non-smokers with $\mathrm{HbAlc} \geq 8.0 \%(64 \mathrm{mmol} / \mathrm{mol})$ showed an association with hearing impairment (HR $(95 \% \mathrm{CI})$ of 1.46 (1.11 to 1.92 ) in men and 2.36 (1.34 to 4.15 ) in women). Although smokers had higher HRs of hearing impairment than non-smokers, HbA1c level was not associated with hearing impairment among smokers. Additional adjustments for job type did not affect the results (online supplementary appendix 1).

Figure 2 shows the spline regression model of high-frequency hearing impairment at various HbAlc levels against a reference HbA1c level of $6.6 \%$ in participants with diabetes at baseline $(n=10154)$. The relationship between HbA1c and the incidence of hearing impairment was J-shaped, with the significant increase of HR for $\mathrm{HbA} 1 \mathrm{c} \geq 7.2 \%$.

\section{DISCUSSION}

In this study, we found a quadratic trend between HbAlc and the incidence of high-frequency hearing impairment. In particular, HbA1c concentrations over 8.0\% (64 $\mathrm{mmol} / \mathrm{mol}$ ) were associated with high-frequency hearing impairment among non-smokers. A J-shaped association between HbAlc and high-frequency hearing impairment 


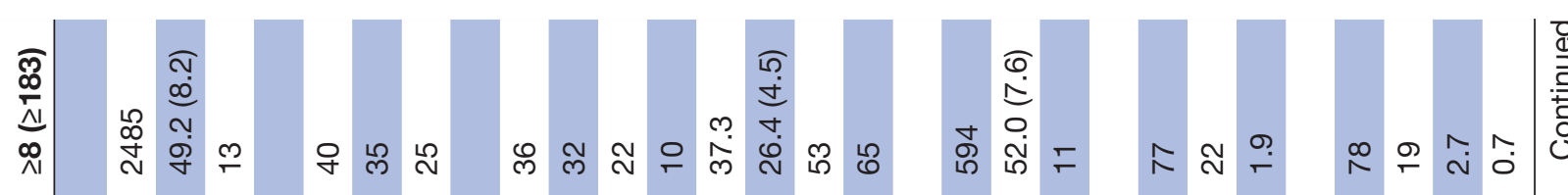<smiles>[13CH]=[131In]</smiles>

\section{旁}

影要

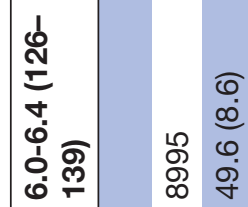

ఠ

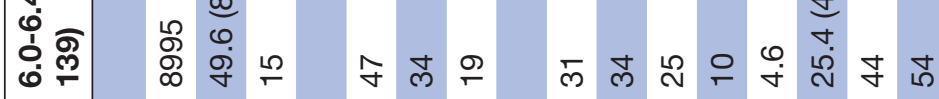

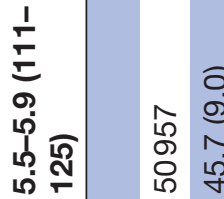

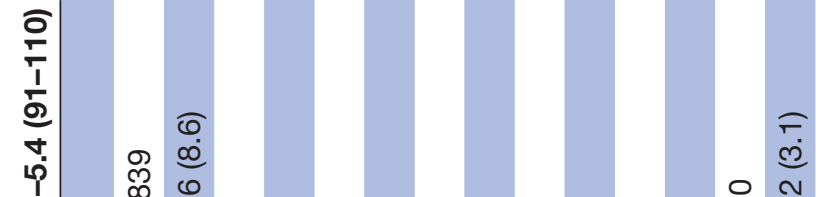

\section{लें}

ம்

\section{ลิ}

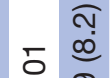

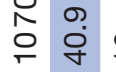

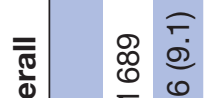

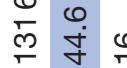

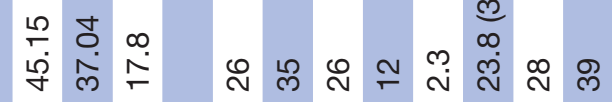

ลิ

๙ุำ

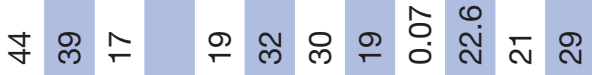

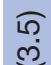

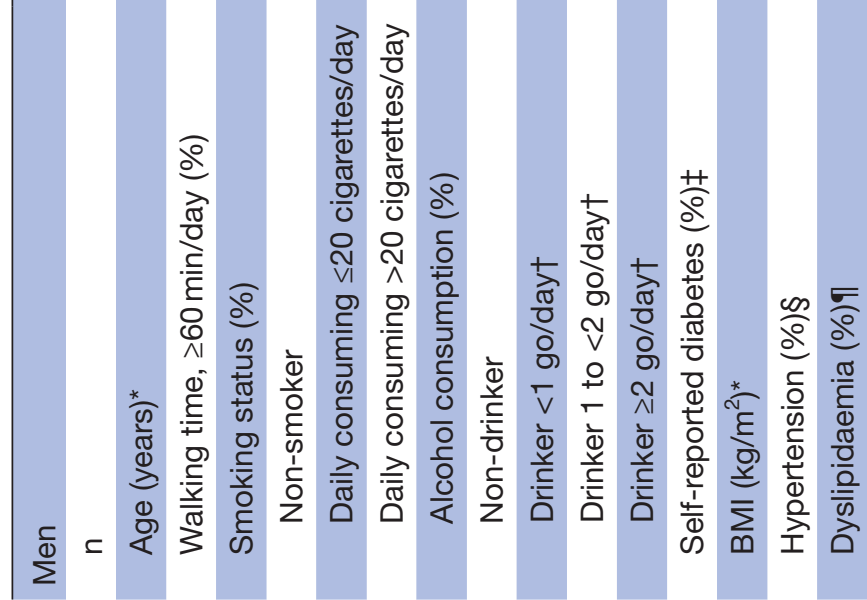

$\hat{\sim} \stackrel{\substack{\infty \\ \infty}}{\infty}$

Q

$\infty \frac{1}{6}$

芥

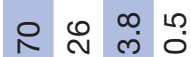

ᄃ

贫

ก

வ 


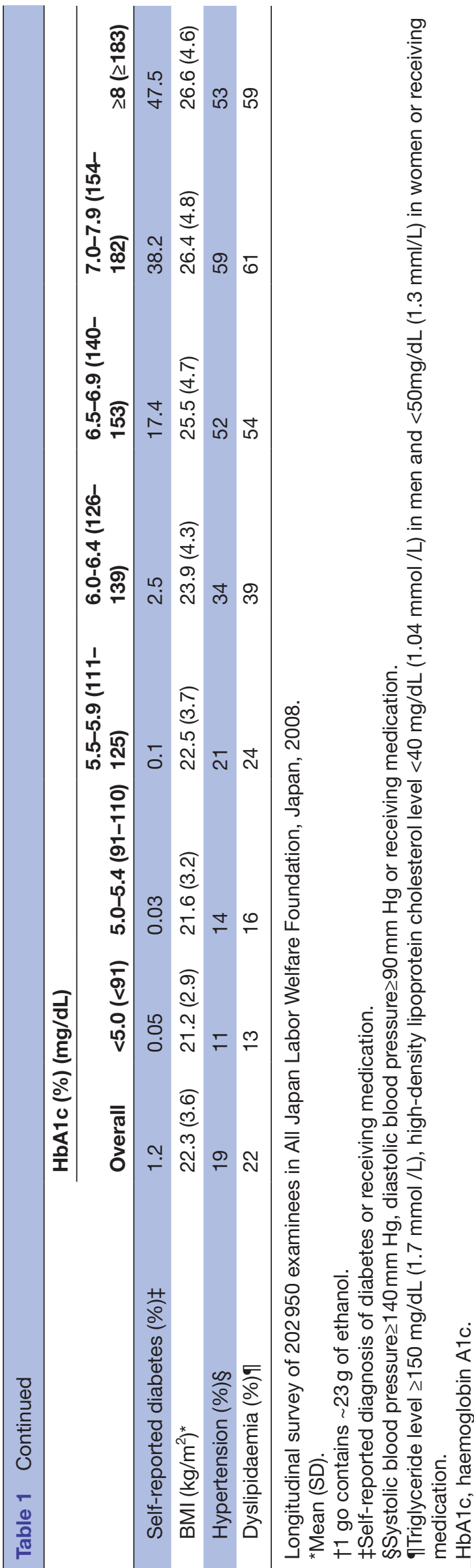

was observed among participants with diabetes at baseline. Our findings indicate that appropriate glycaemic control may prevent the incidence of diabetic hearing impairment.

Our finding of a quadratic trend between HbAlc and hearing impairment is supported by the results of two longitudinal studies. ${ }^{1315}$ One of these reported an OR (95\% CI) of high-frequency hearing impairment per $1.0 \%$ increase in HbA1c of 1.52 (1.03 to 2.23), although no statistical association between the three categories of HbAlc and high-frequency hearing impairment. ${ }^{13}$ The second reported that HbA1c was positively associated with average hearing threshold, mainly among low frequencies. ${ }^{15}$ The present study provides novel evidence that an HbAlc of $8.0 \%(64 \mathrm{mmol} / \mathrm{mol})$ or above is associated with increased risk of high-frequency hearing impairment in non-smokers. Our findings are consistent with the work of Cruickshanks et al, who reported that poor glycaemic control, defined by a glycosylated haemoglobin level, was associated with hearing impairment. ${ }^{23}$

Additionally, we found that the J-shaped association between HbAlc and hearing impairment remained even among participants with diabetes at baseline. This result suggests that proper glycaemic control may prevent diabetic-related hearing impairment even in those with diabetes. Previous studies have also reported a J-shaped association between HbA1c and diabetics complications, and noted that hypoglycaemia might increase diabetic complications. ${ }^{24-26}$ More research is needed to determine a suitable HbA1c level for glycaemic targeting to prevent hearing impairment in diabetic management.

We found that high-frequency hearing impairment has a quadratic trend with HbAlc among non-smokers but not smokers. Previous studies have reported an adverse effect of smoking cigarettes on hearing impairment. ${ }^{23} 2728$ It is plausible that the effect of smoking cigarettes may be stronger than $\mathrm{HbAlc}$ and might mask the effect of HbAlc. Further research is needed to confirm the joint effect of smoking and HbAlc on hearing impairment.

The pathophysiology underlying high-HbAlc-associated hearing impairment is unclear, which allows for speculation. One possible explanation is that hyperglycaemia-related microvascular complications lead to thickening of the cochlea and vestibulopathy, and result in hearing impairment. ${ }^{7829-33}$ Diabetic-related hearing impairment has been mainly observed at high frequencies, suggesting that high frequency-specific areas of the cochlea may be more fragile to ischaemic changes due to microvascular complications. ${ }^{34-38}$ This mechanism is supported by the J-shaped association between HbAlc and hearing impairment observed in the present study, since previous studies also reported a J-shaped-association between HbA1c and diabetic vascular complications. ${ }^{39}{ }^{40}$ Further studies to confirm this idea are required.

This study has several strengths. The large dataset allowed us to investigate the association between HbAlc 


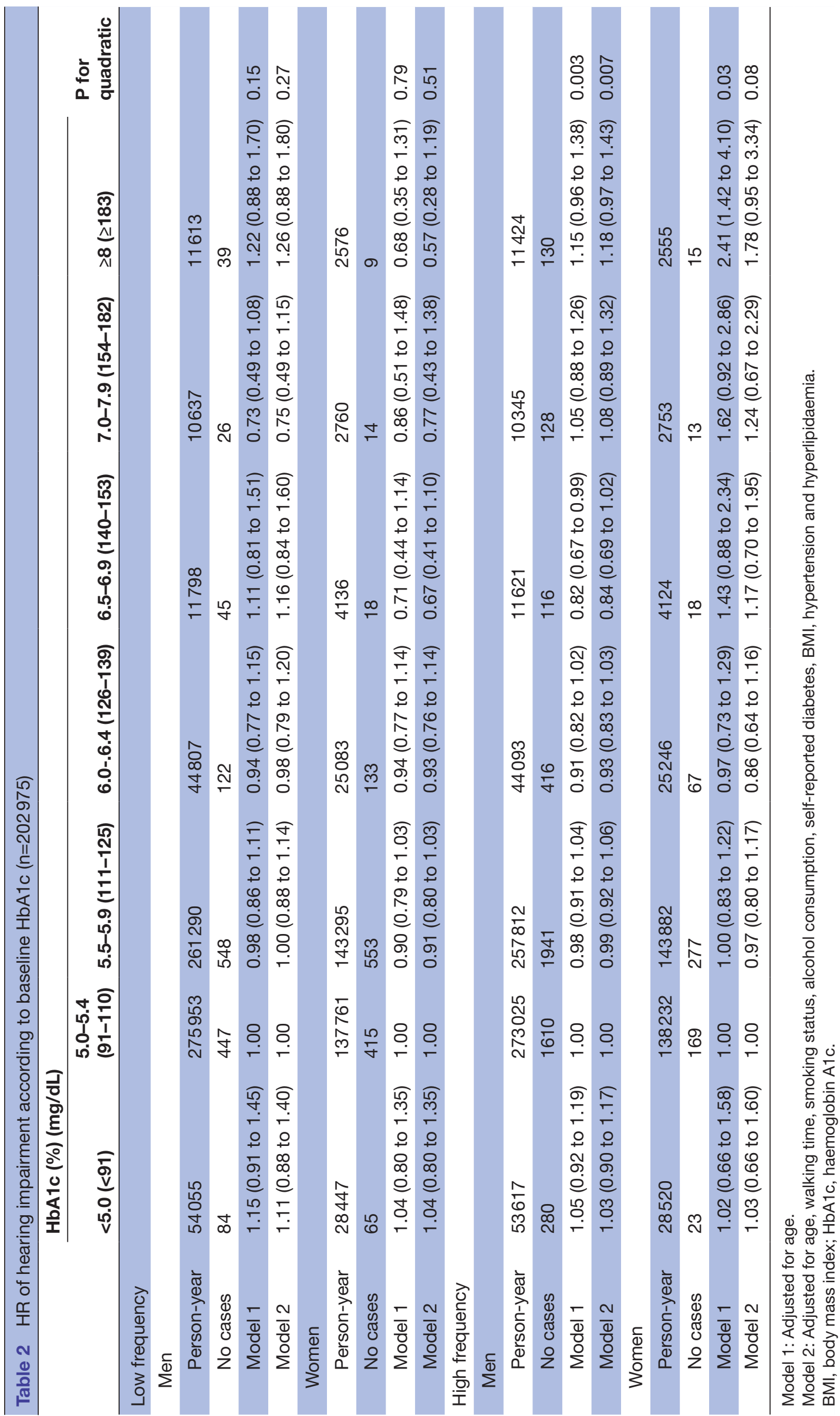




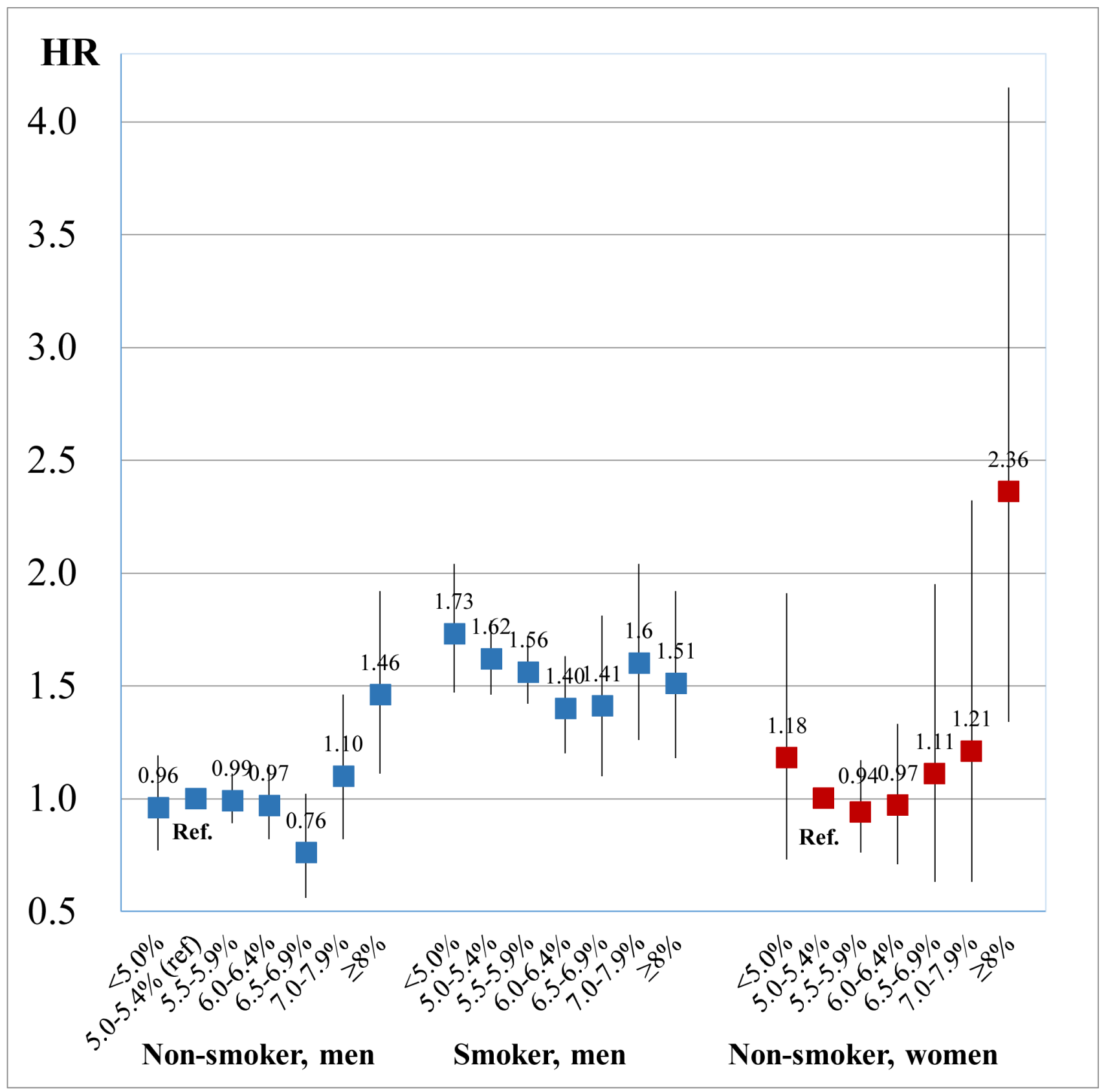

Figure 1 The association between haemoglobin A1c (HbA1c) and hearing impairment of high frequency stratified by smoking status. Results obtained by multivariable Cox regression. The reference value was 5.0\%-5.4\% of HbA1c in non-smoker. The model was adjusted for age (year, continuous), sex, body mass index $\left(<18.5,18.5-22.9,23-29.9 \mathrm{or} \geq 30.0 \mathrm{~kg} / \mathrm{m}^{2}\right)$, alcohol consumption (non-drinker, drinker consuming $<1,1$ to $<2$ or $\geq 2$ go of Japanese sake contains approximately $23 \mathrm{~g}$ of ethanol), walking time ( $<60$ or $\geq 60 \mathrm{~min} /$ day), self-reported diabetes, hypertension (systolic blood pressure $\geq 140 \mathrm{~mm} \mathrm{Hg}$, diastolic blood pressure $\geq 90 \mathrm{~mm} \mathrm{Hg}$ or receiving medication) and hyperlipidaemia (triglyceride level $\geq 150 \mathrm{mg} / \mathrm{dL}$, high-density lipoprotein cholesterol level $<40 \mathrm{mg} / \mathrm{dL}$ or receiving medication).

and hearing impairment with comprehensive adjustment for covariates, and additionally, among participants with diabetes at baseline. Audiometry to confirm hearing impairment was conducted by trained staff. Several limitations of the study also need to be considered. First, though noise exposure is an important risk factor on hearing impairment, ${ }^{41}{ }^{42}$ information on noise exposure was not available, and thus, noise information was not considered in the analyses. The present study thus might include the cofounding influence of noise exposure. However, a previous study reported that the relationship between diabetes and hearing impairment was independent of this variable. ${ }^{37}$ Moreover, in the present study, HbA1c level was associated with hearing impairment even after accounting for job type in a sensitivity analysis. Second, information on ototoxic drug use, ear surgery and ear infection was not collected, and we were therefore unable to exclude cases of hearing impairment 


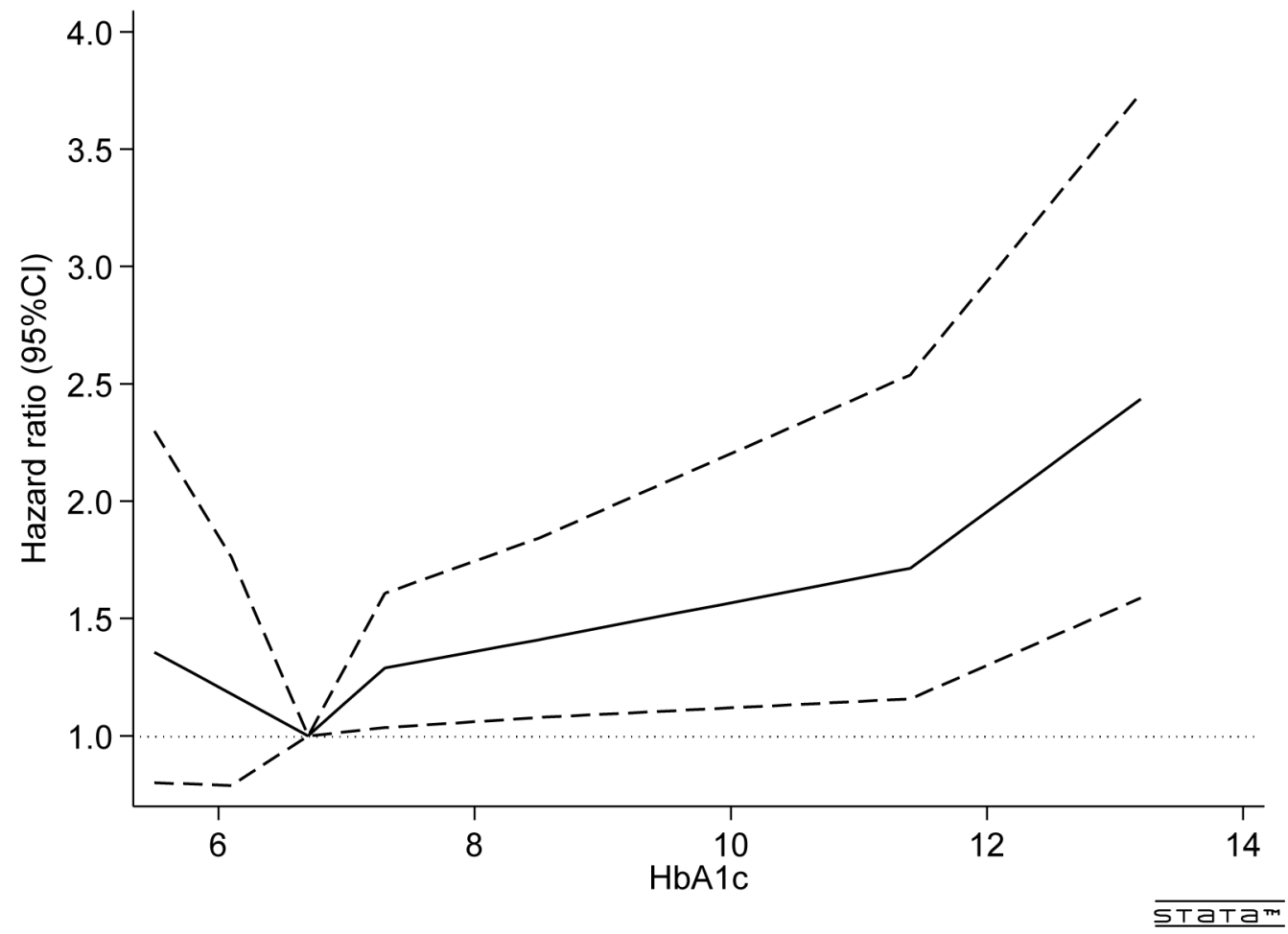

Figure 2 Adjusted HR of high-frequency hearing impairment among participants with diabetes at baseline ( $n=10154)$. Results obtained by multivariable Cox regression with restricted cubic splines with seven knots (p1, p5, p25, p50, p75, p95 and p99). The reference value was $6.6 \%$ (p25) of $\mathrm{HbA} 1 \mathrm{c}$. The continuous line presents HRs and the dashed line presents $95 \% \mathrm{Cls}$. The model was adjusted for age (year, continuous), sex, body mass index $\left(<18.5,18.5-22.9,23-29.9\right.$ or $\left.\geq 30.0 \mathrm{~kg} / \mathrm{m}^{2}\right)$, smoking status (non-smoker, smoker consuming $\leq 20$ or $>20$ cigarettes per day), alcohol consumption (non-drinker, drinker consuming $<1$, 1 to $<2$ or $\geq 2$ go of Japanese sake contains approximately $23 \mathrm{~g}$ of ethanol), walking time ( $<60$ or $\geq 60 \mathrm{~min} /$ day), hypertension (systolic blood pressure $\geq 140 \mathrm{~mm} \mathrm{Hg}$, diastolic blood pressure $\geq 90 \mathrm{~mm} \mathrm{Hg}$ or receiving medication) and hyperlipidaemia (triglyceride level $>150 \mathrm{mg} / \mathrm{dL}$, high-density lipoprotein cholesterol level $<40 \mathrm{mg} / \mathrm{dL}$ in men and $<50 \mathrm{mg} / \mathrm{dL}$ in women or receiving medication). HbA1c, haemoglobin A1c.

due to these factors. Third, blood pressure was measured once, followed by a second measurement if the first systolic blood pressure $\geq 130 \mathrm{~mm} \mathrm{Hg}$ systolic or diastolic blood pressure $\geq 85 \mathrm{~mm} \mathrm{Hg}$. All participants did not have the same evaluation of blood pressure. This may lead to misclassification of hypertension. Fourth, we did not account for gender or smoking status in the association between HbAlc and hearing impairment for participants with diabetes because of the small sample size. Fifth, the hearing test was only conducted at $1 \mathrm{kHz}$ and $4 \mathrm{kHz}$. Hearing impairment at other frequencies could not therefore be identified. Sixth, we cannot exclude the possibility of residual confounding and confounding by unmeasured variables. Finally, the study participants were mainly workers, and thus, caution is required when generalising our findings.

\section{CONCLUSION}

We found the quadratic trend between HbAlc and the incidence of high-frequency hearing impairment in non-smokers. The trend between HbAlc and hearing impairment remained even among those with diabetes.
These findings indicate that diabetic-related hearing impairment may be prevented with appropriate glycaemic control. These findings warrant confirmation in interventional studies.

\section{Author affiliations}

${ }^{1}$ Department of Environmental and Occupational Health, Toho University Graduate School of Medicine, Tokyo, Japan

${ }^{2}$ Division of Occupational Health and Promotion, All Japan Labor Welfare Foundation, Tokyo, Japan

${ }^{3}$ Department of Epidemiology and Prevention, Center for Clinical Sciences, National Center for Global Health and Medicine, Tokyo, Japan

${ }^{4}$ Department of Food and Health Sciences International College of Arts and Sciences, Fukuoka Women's University, Fukuoka, Japan

${ }^{5}$ Department of Nutritional Epidemiology and Shokuiku, National Institutes of Biomedical Innovation, Health and Nutrition, National Institute of Health and Nutrition, Tokyo, Japan

${ }^{6}$ Graduate School of Public Health, Teikyo University, Tokyo, Japan

${ }^{7}$ Environmental Epidemiology Section, Centre for Health and Environmental Risk Research, National Institute for Environmental Studies, Tsukuba, Japan

${ }^{8}$ Department of Medical Statistics, Toho University Graduate School of Medicine, Tokyo, Japan

Acknowledgements The authors would like to thank Nobuo Yanagisawa and Takeshi Kawaguchi for coordinating the study. 
Contributors SN, TaM and IK designed study and drafted the manuscript. SN, HH, KaK, AN and KeK performed the data analysis. MD collected and interpreted the data. All authors participated in interpretation of the findings, revised the paper critically for important intellectual content and approved the final version to be published. YN and YM provided administrative, technical and material support. TeM and SA revised the work critically for important intellectual content. SN and YN are guarantors.

Funding This research was funded by All Japan Labor Welfare Foundation Research Fellowship.

Disclaimer All Japan Labor Welfare Foundation had no role in the design, analysis or writing of this articles.

Competing interests SN is occupational physicians in All Japan Labor Welfare Foundation.

Patient consent Obtained.

Ethics approval The research protocol including consent procedure was approved by the Ethics Committee of the Faculty of Medicine, Toho University (NNo. 25017 and No.A16130) and the Ethics Committee of the National Center for Global Health and Medicine (No. NCGM-G-0 $01254-02$ ).

Provenance and peer review Not commissioned; externally peer reviewed.

Data sharing statement № additional data are available.

Open access This is an open access article distributed in accordance with the Creative Commons Attribution Non Commercial (CC BY-NC 4.0) license, which permits others to distribute, remix, adapt, build upon this work non-commercially, and license their derivative works on different terms, provided the original work is properly cited, appropriate credit is given, any changes made indicated, and the use is non-commercial. See: http://creativecommons.org/licenses/by-nc/4.0/.

\section{REFERENCES}

1. Lin FR, Metter EJ, O'Brien RJ, et al. Hearing loss and incident dementia. Arch Neurol 2011;68:214-20.

2. Li CM, Zhang X, Hoffman HJ, et al. Hearing impairment associated with depression in US adults, National Health and Nutrition Examination Survey 2005-2010. JAMA Otolaryngol Head Neck Surg 2014;140:293-302

3. Herbst KG, Humphrey C. Hearing impairment and mental state in the elderly living at home. Br Med J 1980;281:903-5.

4. Wilson BS, Tucci DL, Merson MH, et al. Global hearing health care: new findings and perspectives. Lancet 2017;390:2503-15.

5. WHO. Deafness and hearing loss. http://www.who.int/mediacentre/ factsheets/fs300/en (accessed 11 Jan 2018).

6. Horikawa C, Kodama S, Tanaka S, et al. Diabetes and risk of hearing impairment in adults: a meta-analysis. J Clin Endocrinol Metab 2013;98:51-8.

7. Fukushima $\mathrm{H}$, Cureoglu S, Schachern PA, et al. Effects of type 2 diabetes mellitus on cochlear structure in humans. Arch Otolaryngol Head Neck Surg 2006;132:934-8.

8. Oron Y, Elgart K, Marom T, et al. Cardiovascular risk factors as causes for hearing impairment. Audiol Neurootol 2014;19:256-60.

9. Klein R, Klein BE, Moss SE. Relation of glycemic control to diabetic microvascular complications in diabetes mellitus. Ann Intern Med 1996;124(1 Pt 2):90-6.

10. Danne T, Weber B, Dinesen B, et al. Threshold of HbA1c for the effect of hyperglycemia on the risk of diabetic microangiopathy. Diabetes Care 1996;19:183.

11. Li W, Katzmarzyk PT, Horswell R, et al. HbA1c and all-cause mortality risk among patients with type 2 diabetes. Int $J$ Cardiol 2016;202:490-6.

12. American Diabetes Association. 5. Glycemic Targets. Diabetes Care 2016;39(Suppl 1):S39-46.

13. Michikawa T, Mizutari K, Saito H, et al. Glycosylated hemoglobin level is associated with hearing impairment in older Japanese: the Kurabuchi Study. J Am Geriatr Soc 2014;62:1231-7.

14. Kang SH, Jung DJ, Cho KH, et al. Association Between HbA1c Level and Hearing Impairment in a Nondiabetic Adult Population. Metab Syndr Relat Disord 2016;14:129-34.

15. Kim MB, Zhang Y, Chang Y, et al. Diabetes mellitus and the incidence of hearing loss: a cohort study. Int J Epidemiol 2017;46:717-26.

16. Japan Industrial Safety and Health Association (English Page). Ordinance on Industrial Safety and Health, Article 44 Periodical Medical Examination, (iii). http://www.japaneselawtranslation.go.jp/ law/detail_main?re=01\&ia=03\&vm=02\&id=1984 (accessed 11 Jan 2018).
17. Rigters SC, Metselaar M, Wieringa MH, et al. Contributing Determinants to Hearing Loss in Elderly Men and Women: Results from the Population-Based Rotterdam Study. Audiol Neurootol 2016;21(Suppl 1):10-15.

18. Helzner EP, Cauley JA, Pratt SR, et al. Race and sex differences in age-related hearing loss: the Health, Aging and Body Composition Study. J Am Geriatr Soc 2005;53:2119-27.

19. Ministry of Health, Labour and Welfare (English Page). Specific health checkups and specific health guidance. http://www.mhlw.go.jp/ english/wp/wp-hw3/dl/2-007.pdf (accessed 11 Jan 2018).

20. Ministry of Health, Labour and Welfare (Japanese Page). Health guidance questionnaire. http://www.mhlw.go.jp/seisakunitsuite/ bunya/kenkou_iryou/kenkou/seikatsu/dl/hoken-program2_02.pdf (accessed 11 Jan 2018).

21. Kashiwagi A, Kasuga M, Araki E, et al. International clinical harmonization of glycated hemoglobin in Japan: From Japan Diabetes Society to National Glycohemoglobin Standardization Program values. J Diabetes Investig 2012;3:39-40.

22. Harrell F. Regression modeling strategies: with applications to linear models, logistic and ordinal regression and survival analysis. New York: Springer International Publishing, 2015.

23. Cruickshanks KJ, Nondahl DM, Dalton DS, et al. Smoking, central adiposity, and poor glycemic control increase risk of hearing impairment. J Am Geriatr Soc 2015;63:918-24.

24. Carson AP, Fox CS, McGuire DK, et al. Low hemoglobin A1c and risk of all-cause mortality among US adults without diabetes. Circ Cardiovasc Qual Outcomes 2010;3:661-7.

25. Goto A, Noda M, Matsushita Y, et al. Hemoglobin a1c levels and the risk of cardiovascular disease in people without known diabetes: a population-based cohort study in Japan. Medicine 2015:94:e785

26. Snell-Bergeon JK, Wadwa RP. Hypoglycemia, diabetes, and cardiovascular disease. Diabetes Technol Ther 2012;14(Suppl 1):S51-50.

27. Barone JA, Peters JM, Garabrant DH, et al. Smoking as a risk factor in noise-induced hearing loss. J Occup Med 1987;29:741-5.

28. Nomura K, Nakao M, Morimoto T. Effect of smoking on hearing loss: quality assessment and meta-analysis. Prev Med 2005;40:138-44.

29. Lisowska G, Namysłowski G, Morawski K, et al. Cochlear dysfunction and diabetic microangiopathy. Scand Audiol Suppl 2001;52:199-203.

30. Akinpelu OV, Ibrahim F, Waissbluth S, et al. Histopathologic changes in the cochlea associated with diabetes mellitus-a review. Otol Neurotol 2014;35:764-74.

31. Krogsbøll LT, Jørgensen KJ, Grønhøj Larsen C, et al. General health checks in adults for reducing morbidity and mortality from disease. Cochrane Database Syst Rev 2012;11:e7191.

32. Kaźmierczak H, Doroszewska G. Metabolic disorders in vertigo, tinnitus, and hearing loss. Int Tinnitus J 2001;7:54-8.

33. Nash SD, Cruickshanks KJ, Klein R, et al. The prevalence of hearing impairment and associated risk factors: the Beaver Dam Offspring Study. Arch Otolaryngol Head Neck Surg 2011;137:432-9.

34. Uchida Y, Sugiura S, Ando F, et al. Diabetes reduces auditory sensitivity in middle-aged listeners more than in elderly listeners: a population- based study of age-related hearing loss. Med Sci Monit 2010;16:Ph63-8.

35. Konrad-Martin D, Reavis KM, Austin D, et al. Hearing impairment in relation to severity of diabetes in a veteran cohort. Ear Hear 2015;36:381-94.

36. Bainbridge KE, Hoffman HJ, Cowie CC. Risk factors for hearing impairment among U.S. adults with diabetes: National Health and Nutrition Examination Survey 1999-2004. Diabetes Care 2011;34:1540-5

37. Bainbridge KE, Hoffman HJ, Cowie CC. Diabetes and hearing impairment in the United States: audiometric evidence from the National Health and Nutrition Examination Survey, 1999 to 2004. Ann Intern Med 2008;149:1-10.

38. Kim JS, Lee H. Inner ear dysfunction due to vertebrobasilar ischemic stroke. Semin Neurol 2009;29:534-40.

39. Huang ES, Liu JY, Moffet HH, et al. Glycemic control, complications, and death in older diabetic patients: the diabetes and aging study. Diabetes Care 2011;34:1329-36.

40. Östgren CJ, Sundström J, Svennblad B, et al. Associations of HbA1c and educational level with risk of cardiovascular events in 32,871 drug-treated patients with Type 2 diabetes: a cohort study in primary care. Diabet Med 2013;30:e170-7.

41. Lie A, Skogstad M, Johannessen HA, et al. Occupational noise exposure and hearing: a systematic review. Int Arch Occup Environ Health 2016;89:351-72.

42. Henderson D, Bielefeld EC, Harris KC, et al. The role of oxidative stress in noise-induced hearing loss. Ear Hear 2006;27:1-19. 